FACULDADE DE CIÊNCIAS ECONÔMICAS DA UFRGS Análise
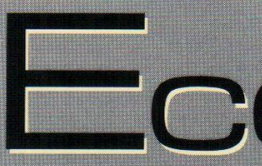

VALORES E PREÇOS DE PRODUÇÃO: UMA RELETURA de MARX Alfredo SAAD FILHO

OS ANTIGOS, OS NOVOS E OS NEO-INSTITUCIONALISTAS: HÁ CONVERGÉ NCIA TEÓ RICA NO PENSAMENTO INSTITUCIONALISTA

Octavio Augusto C. Conceição

A MENSURAÇÃ O DO GRAU DE INDEPENDÉNCIA DO BANCO CENTRAL: UMA ANÁLISE DE SUAS FRAGILIDADES HeLder Ferreira de MENDONÇA

A SUSTENTABILIDADE DA DÍVIDA MOBILIÁ RIA FEDERAL BRASILEIRA: UMA INVESTIGAÇĀ O ADICIONAL VIVIANE LUPORINI

O MODELO dE KRUGMAN EXPLICA A CRISE CAMBIAL. BRASILEIRA EM JANEIRO DE 1999?

Adriano CAMPOS MENEZES E TITO BELCHIOR S. MOREIR/

ESTRANGULAMENTO DA díVIDA EXTERNA E CRESCIMENTO ECONO MICO NA AMÉRICA LATINA: LIÇÓ ES DA DÉCADA DE 80

Marco Vaies buratto E SABino da SiLva P. JR.

CriaÇÃo e desvio de COMÉrCio: ANÁlise do FLuXo COMERCial ENTRE O Brasil. e O MERCOSUl para Alguns PRODUTOS INDUSTRIALIZADOS

Clá Udio Roberto fó fFano Vasconcelos

A EVOLUCÁ̃ DA INDÚ STRIA BRASILEIRA DE CELULOSE E SUA ATUAÇÃO NO MERCADO MUNDIAL

Emerson Martins HILGemberg e Carlos josé Caetano BACHA

A PROTEÇÃo SOCIAL NO PRIMEIRO QUARTEL DO SÉCULO XXI: BRINCANDO COM CENÁRIOS

rosa Maria Marques e Áquilas Mendes

ECONOMIA DO CRIME: ELEMENTOS TEÓ RICOS E EVIDÊNCIAS EMPÍRICAS

Gilberto José SChaefer e Pery Francisco Assis Shikida

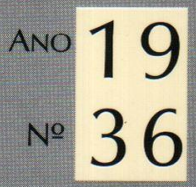


UNIVERSIDADE FEDERAL DO RIO GRANDE DO SUL

Reitora: Profa. Wrana Maria Panizzi

FACULDADE DE CIÊNCIAS ECONÔMICAS

Diretor: Prof. Pedro Cézar Dutra Fonseca

CENTRO DE ESTUDOS E PESQUISAS ECONÔMICAS

Diretor: Prof. Gentil Corazza

DEPARTAMENTO DE CIÊNCIAS ECONÔMICAS

Chefe: Prof. Luiz Alberto Oliveira Ribeiro de Miranda

DAPARTAMENTO DE CIÊNCIAS CONTÁBEIS E ATUARIAIS

Chefe: João Marcos Leão da Rocha

CURSO DE PÓS-GRADUAÇÃO EM ECONOMIA

Coordenador: Prof. Eduardo Pontual Ribeiro

CURSO DE PÓS-GRADUAÇÃO EM ECONOMIA RURAL

Coordenador: Prof. Jalcione Almeida

CONSELHO EDITORIAL: Achyles B. Costa, Aray M. Feldens, Carlos A. Crusius, Carlos G. A. Mielitz Netto, Eduardo A. Maldonado Filho, Eduardo P. Ribeiro, Eugênio Lagemann, Fernando Ferrari Filho, Gentil Corazza, Jan A. Kregel (Univ. of Bologna), Marcelo S. Portugal, Nali J. Souza, Otilia B. K. Carrion, Paulo A. Spohr, Paulo D. Waquil, Pedro C. D. Fonseca, Philip Arestis (Univ of East London), Roberto C. Moraes, Ronald Otto Hillbrecht, Stefano Florissi, Eleutério F. S. Prado (USP), Fernando H. Barbosa (FGV/RJ), Gustavo Franco (PUC/RJ), João R. Sanson (UFSC), Joaquim P. Andrade (UnB), Juan H. Moldau (USP), Paul Davidson (Univ. of Tennessee), Werner Baer (Univ. of Illinois).

COMISSÃO EDITORIAL: Eduardo Augusto Maldonado Filho, Fermando Ferrari Filho, Gentil Corazza, Marcelo Savino Portugal, Paulo Dabdab Waquil; Roberto Camps Moraes.

EDITOR: Fernando Ferrari Filho

EDITOR ADJUNTO: Pedro Silveira Bandeira

SECRETÁRIA: Vanessa Hoffmann de Quadros

REVISÃO DE TEXTOS: Vanete Ricacheski

FUNDADOR: Prof. Antônjo Carlos Santos Rosa

Os materiais publicados na revista Análise Econômica sāo da exclusiva responsabilidade dos autores. É permitida a reproduçāo total ou parcial dos trabalhos, desde que seja citada a fonte. Aceita-se permuta com revistas congêneres. Aceitam-se, também, livros para divulgação, elaboração de resenhas e recensões. Toda correspondência, material para publicação (vide normas na terceira capa), assinaturas e permutas devem ser dirigidos ao seguinte destinatário:

PROF. FERNANDO FERRARI FILHO

Revista Análise Econômica - Av. João Pessoa, 52 CEP 90040-000 PORTO ALEGRE - RS, BRASIL Telefones: (051) 316-3348 e 316-3440 - Fax: (051) 316-3990

E-mail: rae@vortex.ufrgs.br

Análise Econômica

Ano 18, n⿳3 33, março, 2000 - Porto Alegre

Faculdade de Ciências Econômicas, UFRGS, 2000

Periodicidade semestral, março e setembro.

1. Teoria Econômica - Desenvolvimento Regional -

Economia Agrícola - Pesquisa Teórica e Aplicada -

Periódicos. I. Brasil

Faculdade de Ciências Econômicas,

Universidade Federal do Rio Grande do Sul.

CDD 330.05

CDU 33 (81) (05) 


\title{
A proteção social no primeiro quartel do século XXI: brincando com cenários
}

Rosa Maria Marques ${ }^{1}$ e Áquilas Mendes ${ }^{2}$

\begin{abstract}
Resumo: Este artigo trata do futuro da Proteção Social. Na primeira parte, é discutida a natureza e o alcance das medidas e reformas implementadas em diferentes países desenvolvidos e no Brasil, para fazerem frente às crescentes dificuldades financeiras dos sistemas públicos a partir de meados da década de 70 e à nova realidade do mundo do trabalho. Na segunda parte, a partir da construção de dois cenários macroeconômicos, é analisado o provável impacto na Proteção Social em termos de concepção, organização e cobertura.
\end{abstract}

Palavras-chave: Proteção Social; Reformas; Financiamento da proteção social.

\begin{abstract}
The present article examines the future of social protection. Firstly, it discusses the nature and the achievements of measures and reforms implemented in developed countries and in Brasil, due to increasing financial difficulties in public systems, particularly from the decade of 70 s onwards, and to the new reality of the working world. Secondly, considering the construction of two macroeconomic scenarios, it analyses the probable impact on social protection in terms of conception, organization and coverage.
\end{abstract}

Key words: social protection; reforms; social protection financing.

\section{Introdução}

Há exatamente 25 anos, desde que o mundo capitalista foi surpreendido pelos primeiros indícios de que algo não ia bem no círculo virtuoso do padrão de acumulação fordista, que os governantes e especialistas de diferentes matizes advogam o fim dos sistemas de proteção social construídos e desenvolvidos no período do pós-guerra. Durante esse tempo, contudo, apesar de o pensamento liberal ter obtido importantes vitórias, essas basicamente resultaram nas reformas ocorridas na América Latina, pois, no centro do Welfare State, os avanços não chegaram a descaracterizar as estruturas existentes ${ }^{3}$.

\footnotetext{
${ }^{1}$ Professora associada do Departamento de Economia da PUC/SP e consultora da Fundação Seade 2 Professor da Faculdade de Economia da FAAP e técnico do CEPAM.

${ }^{3}$ Sobre a Reforma e a América Latina, ver Marques (2000)
} 
Entretanto, não há como negar que os fatores que animaram os primeiros diagnósticos com relação à necessidade de reformas radicais não só se mantêm presentes como fortalecidos: elevadas taxas de desemprego; crescimento medíocre das economias; e envelhecimento da população. A esses fatores se deve acrescentar o objetivo estratégico de combate ao déficit público, definido pela União Monetária Européia (UME), através do Pacto de Estabilidade e Crescimento, como necessariamente inferior a 3\% do PIB, e, no caso do Brasil, definido pelo Fundo Monetário Internacional. Nas duas situações, a busca do equilíbrio fiscal ou de superávit significa a inviabilidade da utilização da política fiscal como instrumento da sustentação da demanda ${ }^{4}$.

É possivel que esses constrangimentos acabem por se fazer valer e exijam a construção de outro tipo de proteção social ou até mesmo coloquem em questão qualquer tipo de proteção social, entendida como algo emanado da idéia do coletivo? Após analisar as medidas implementadas nos últimos 25 anos, esse texto, na tentativa de responder a essas perguntas, faz um exercício a partir de dois cenários.

Antes, porém, uma observação se faz necessária. Keynes, no capítulo Estado das Expectativas a Longo Prazo, observa que, ao se formarem as expectativas quanto ao futuro, faz parte da natureza humana atribuir maior importância às variáveis sobre as quais temos maior conhecimento e menor peso àquelas sobre as quais pouco sabemos. Como essas últimas podem alterar os resultados, as projeções, por melhor que tenham sido os instrumentos utilizados, podem se mostrar, no futuro, redondamente equivocadas. Exatamente por isso, Keynes destaca que o relevante, para a tomada de decisões, é o grau de confiança que temos no prognóstico realizado. Nesse sentido, o método utilizado para fazê-lo deixa de ser importante: tanto faz se foi fundado na leitura de cartas ou em sofisticadas projeções realizadas por uma equipe de consultores. Evidentemente que Keynes estava se referindo a situaçóes onde lhe interessava enfatizar o quanto o investimento era determinado pela subjetividade daquele que tinha o poder de decidir se iria investir ou não. Embora esse não seja o objeto deste exercício, fica a ressalva de que é impossível realizar projeções sem correr o risco de que o elemento desconhecido venha a demonstrar a falsidade dos prognósticos.

$\mathrm{Na}$ tentativa de diminuir a probabilidade do erro, esse estudo discute como será a proteção social no mundo de 2025 a partir da cons-

4 Para uma análise das implicações da União Monetária Européia, ver Arestis e Sawyer (1999). 
trução de dois cenários. Mesmo assim, não se pode afirmar, com segurança, que não estamos trabalhando no campo da ficção. O que nos anima é saber que, inúmeras vezes, a realidade concreta ocorre tal como previsto ou imaginado no campo da ficção. Sem dúvida, as semelhanças entre o real e a ficção - apenas diferidas no tempo - são mais facilmente verificadas quanto se trata de ocorrências que envolvam a utilização de novas tecnologias. Contudo, como bem descrevem os melhores autores da ficção científica, seu uso generalizado altera comportamentos e relações, sejam elas sociais, políticas e econômicas.

O artigo está divido em seis partes. Na segunda, discutimos os principais constrangimentos da proteção social e, na terceira, descrevemos as mudanças ocorridas nos anos de crise. Já na quarta, abordamos o cenário I, em que o pressuposto é a continuidade da crise, enfocando como seria afetada a proteção social nos países desenvolvidos e no Brasil. Na quinta, trabalhamos com o cenário II, em que o suposto é o retorno do círculo virtuoso do capitalismo. Finalmente, na sexta parte, tecemos algumas considerações finais.

\section{Os principais constrangimentos da Proteção Social}

Dentre os fatores que atuam negativamente sobre o financiamento da proteção social dos chamados países desenvolvidos, três se destacam como principais: o fraco crescimento das economias; a persistência das elevadas taxas de desemprego e a continuidade do processo de envelhecimento da população. A persistência desses fatores, que atuam de forma combinada e imbricada, tem reforçado a convicção dos que consideram que o tempo da proteção social fundada no trabalho já se esgotou, fazendo-se necessário o surgimento de outras formas de garantia de renda.

Há quem atribua às novas tecnologias - principalmente às com base técnica na microeletrônica - o motivo das economias não estarem criando os postos de trabalho necessários para atender à oferta de trabalho (Gorz, 1982 e Rifkin, 1995). Esses analistas consideram que a produtividade inerente ao uso das novas tecnologias é tal que a forte redução da taxa de crescimento populacional, observada nas últimas décadas, tem sido incapaz de atenuar o impacto negativo sobre o mercado de trabalho.

Esse tipo de abordagem é, contudo, contestado por vários pesquisadores (Chesnais, 1995 e Mattoso, 1994 e 1999). Apesar das novas 
tecnologias, o aumento da produtividade observada nas economias desenvolvidas ocorre a níveis muito mais baixos do que aqueles do período de auge da acumulação fordista (Tabela 1). Mais do que isso, observa-se que, para alguns países, tais como Japão e Estados Unidos, o crescimento ocorre a taxas cada vez menores.

Tabela 1: Evolução da Produtividade - produção por trabalhador empregado (média anual em \%)

\begin{tabular}{|c|c|c|c|c|c|c|c|}
\hline & $1970 / 60$ & $1973 / 70$ & $1976 / 73$ & $1979 / 76$ & $1982 / 79$ & $1989 / 79^{*}$ & $1997 / 79^{* *}$ \\
\hline França & 4,9 & 5,1 & 2,7 & 3,0 & 1,6 & 2,0 & \\
\hline RFA & 4,5 & 3,6 & 3,1 & 3,0 & 0,8 & - & \\
\hline Reino Unido & 2,6 & 3,3 & 1,0 & 1,7 & 2,1 & 1,7 & \\
\hline Itália & 6,2 & 4,0 & 1,0 & 3,0 & 0,6 & 2,1 & \\
\hline EUA & 1,9 & 2,7 & 0,2 & 0,8 & 0,0 & 1,1 & 0,9 \\
\hline Japão & 11,2 & 6,4 & 1,9 & 3,9 & 2,2 & 3,0 & \\
\hline União Européia & & . & & & & & 1,9 \\
\hline
\end{tabular}

Fontes: INSEE Citado por Mistral e Boyer, 1982; * OCDE Citado por Mattoso (1994);

** OCDE. Citado por Mattoso, 1999.

A generalização do que é observado em uma determinada planta ou setor de atividade é um dos erros metodológicos mais comuns e mais antigos no campo da economia, principalmente entre aqueles que perseguem o pensamento neoclássico. Os ganhos de produtividade indubitáveis das novas tecnologias não se constituem gerais exatamente porque sua introdução no aparelho produtivo acontece em uma situação de retração da demanda, servindo muito mais para reduzir o custo das empresas que lutam por se manter no mercado, do que para ampliar sua participação.

Dessa forma, o principal elemento inibidor da demanda por trabalho fica por conta do fraco desempenho das economias desenvolvidas ${ }^{5}$, com

${ }^{5}$ A taxa de crescimento médio do G-7 (Estados Unidos, Canadá, Alemanha, Itália, França, Reino Unido e Japăo) é decresçente após o início da crise ( $3,6 \%$ para os anos $70 ; 2,8 \%$ para a década de 80 e $2,0 \%$ para os anos 90 ). Na segunda metade da década de 70 , a taxa de crescimento da economia capitalista caracterizava-se por ser a metade daquela dos anos 50 e 60 . 
exceção do ocorrido nos Estados Unidos ${ }^{6}$. Nessa situação, o desemprego se mantém elevado, embora tenha recuado na Espanha e um pouco nos demais países ${ }^{7}$. Contudo, é possível que essa queda deva-se, em parte, ao desalento dos desempregados, que cansados de procurarem emprego em vão, retiram-se da população economicamente ativa.

A manutenção de altas taxas de desemprego e o crescimento do desemprego de longa duração dificulta sobremaneira o financiamento dos sistemas de proteção social, principalmente daqueles largamente financiados com contribuições de empregados e empregadores (França, Itália, Espanha e Portugal) ${ }^{8}$. Isso porque, de um lado, reduzem a entrada de novos contribuintes e, de outro, aumentam o número de trabalhadores necessitados de algum tipo de garantia de renda. Essa situação é chamada, no jargão previdenciário, de diminuição da relação contribuintes/segurados.

A redução relativa dos contribuintes torna-se ainda mais preocupante quando ocorre em países onde a participação da população idosa (com mais de 65 anos) é significativa e onde a esperança de sobrevida (para essa faixa de idade) é crescente. O aumento dos anos de permanência no sistema dessa faixa da população - recebendo aposentadorias e pensões -, constitui despesa cada vez mais importante.

Contudo, até o momento, essas dificuldades, ao lado de outras medidas que serão mencionadas abaixo, têm sido respondidas através do aumento do aporte de recursos fiscais. Nesses países, ao contrário do que sempre ocorreu no Brasil, a participação do Estado no financiamento da proteção social sempre foi importante, mesmo para aqueles em que as contribuições calculadas sobre o salário constituem a principal fonte de recursos (Marques, 1997).

Esse movimento explica, em grande medida, por que houve aumento da despesa com Proteção Social nas últimas décadas, apesar da crise. Evidentemente que o maior aporte de recursos do Estado significa que a sociedade está sancionando demandas de vários tipos: as de-

\footnotetext{
${ }^{6}$ Os Estados Unidos constituem a exceção no mundo, mantendo taxas relativamente altas de crescimento do PIB e quase nenhum desemprego, porque não sofrem nenhuma restrição de ordem externa. Sua posição privilegiada no contexto internacional thes permitem mais do que financiar o déficit da balança de transações correntes.

${ }^{7} \mathrm{Na}$ Espanha, a taxa de desemprego de 22,9\%, em 1995, caiu para 15,8\% em 1999.

${ }^{8} \mathrm{Em}$ 1995, em torno de 65\% do financiamento da proteçāo social da União Européia eram garantidos pelas contribuições das empresas e dos segurados. Desse percentual, os empregadores respondiam por 40 pontos percentuais (European Commission, 1998).
} 
correntes do envelhecimento da população, do crescimento do desemprego, da difusão de tecnologias modernas na área da saúde e do aumento da participação da mulher no mercado de trabalho, o que provocou a necessidade de o Estado prover equipamentos para cuidados de crianças e idosos (European Commission, 1998). O fato de essas demandas terem resposta é indicativo não só do quanto os países europeus estão ainda impregnados dos princípios que impulsionaram a construção do Welfare State, como também de serem sociedades democráticas, em que a pressão e resistência dos interessados na manutenção dos sistemas de proteção social são ouvidas e consideradas. A Tabela 2 apresenta, para alguns países e anos, o quanto a despesa com Seguridade Social em relação ao PIB cresceu nas últimas décadas.

Tabela 2: Despesas com Seguridade Social (\% do PIB)

\begin{tabular}{c|c|c|c|c|c}
\hline Países & 1960 & 1970 & 1980 & 1990 & $1995^{* *}$ \\
\hline EUA & 7,3 & 10,4 & 12,0 & 14,5 & - \\
\hline CEE & 4,1 & 5,7 & 10,5 & 11,5 & 28,5 \\
\hline Alemanha & 18,1 & 19,5 & 25,4 & $24,0^{*}$ & 29,0 \\
\hline Reino Unido & 10,2 & 13,2 & 16,4 & $20,3^{*}$ & 27,5 \\
\hline França & 13,2 & 16,7 & 23,5 & 26,6 & 30,0 \\
\hline Grécia & 7,0 & 9,0 & 11,0 & 20,6 & 21,0 \\
\hline Suécia & 10,8 & 16,7 & 32,4 & 33,9 & 35,5 \\
\hline
\end{tabular}

$\left.{ }^{*}\right)$ Refere-se à média de 1988-89.

Fontes: OCDE; ** Eurostat.

\section{As reformas dos sistemas de proteção social e seus limites}

Os constrangimentos ao financiamento dos sistemas de proteção social deram lugar a dois tipos básicos de ação. De um lado, os governos buscaram elevar a participação no custeio dos usuários e dos contribuintes, muito embora tenham aumentado a participação dos recursos fiscais no financiamento, e, de outro, procuraram atuar sobre as condições de oferta e demanda dos benefícios e serviços concedidos pela proteção social. Paralelamente a isso, acompanhando o ressurgimento do pensamento liberal no campo estrito da economia, representantes de diversos governos, de organismos internacionais e formadores de opinião passaram a defender o fim dos sistemas organizados 
pelo Estado, que se fundam sobre os princípios solidários da repartição simples na esfera previdenciária ou do acesso universal no campo da saúde. Como veremos, as propostas de reformulação completa da proteção social não tiveram, até o momento, eco em nenhum país desenvolvido. As experiências se resumem a pequenos países latino-americanos, em que a proteção social anterior às reformas não pode ser caracterizada como universal, seja do ponto de vista da cobertura da população, como da concessão de beneficios iguais para os diferentes tipos de segurados.

\subsection{Maior esforço dos contribuintes, redução do tempo de concessão e dos benefícios}

No campo previdenciário, uma das primeiras respostas encontradas pelos governos à deterioração da situação financeira dos sistemas de proteção social, largamente financiados por contribuições sociais calculadas sobre os salários, foi exigir maior participação dos contribuintes, principalmente dos trabalhadores. Na França, por exemplo, entre 1975 e 1982, a aliquota das contribuiçōes sociais (sob teto) ao encargo dos assalariados aumentou em 4,18 pontos percentuais ( 2 pontos para doença; 1,7 para velhice e 0,48 para a UNEDIC (União Nacional Interprofissional para o Emprego na Indústria e Comércio) (Unicamp, 1986). Já D'Intignano denuncia que, em 10 anos, a contribuição dos trabalhadores aumentou de $4,9 \%$ para $6,5 \%$ do PNB (Produto Nacional Bruto), enquanto a participação dos empregadores permaneceu constante, fixada em 14,8\% do PNB (D'Intignano, 1993).

$O$ aumento das alíquotas para fazer frente a desequilíbrios financeiros sempre foi usual entre os administradores dos sistemas de proteção social em situações de crise conjuntural. Contudo, como sua eficácia diminui à medida que o contexto de desemprego massivo permanece, pode-se afirmar que os governantes deram prosseguimento a esse instrumento enquanto não criaram as condições políticas e institucionais que lhes possibilitassem fazer uso de outros instrumentos. Já fazer recair o aumento da contribuição sobre os trabalhadores fundou-se na convicção de que maiores encargos para os empregadores teriam impacto negativo sobre a competitividade das empresas e o nivel de emprego.

A redução dos valores dos beneficios é praticada através de três mecanismos. O primeiro deles trabalha com o grau de indexação sobre a inflação passada, o que resulta na recomposição parcial do poder 
aquisitivo do benefício ou na manutenção de seu valor nominal. A prática de indexar parcialmente à inflação passada foi bastante utilizada nos anos 70 e 80 , quando o custo de vida aumentou significativamente nas economias desenvolvidas. Nos últimos anos, é possível encontrarse situações como a da Finlândia, em que os benefícios pagos em 1997 não incorporaram a perda do poder aquisitivo ocasionada pela inflação de 1995 e 1996. A indexação parcial ocorreu recentemente na França, na Espanha, na Alemanha e na Suécia.

O segundo mecanismo utilizado para diminuir o valor dos beneficios altera sua relação com o salário da ativa. Essa medida, contudo, tem suscitado muita discussão e, em alguns casos, tem obrigado a que governos restaurem em parte o direito perdido. Esse é o caso da Suécia, que depois de promover reduçōes sucessivas (em 1996 diminuiu de $80 \%$ para $75 \%$; anteriormente o percentual correspondia a $90 \%$ do salário), voltou a conceder 80\% em 1997 (European Commission, 1998).

Em outros países, essa redução foi obtida mediante a ampliação do número de anos que entram no cálculo da aposentadoria, o que leva a média para baixo. Esse foi o caso de Portugal, Áustria e Finlândia. Em outros, tal como na Grécia, além da diminuição do percentual sobre o salário da ativa, o teto máximo de benefício foi reduzido. Vale mencionar, ainda, que a reforma alemá contempla o uso de um fator demográfico para o cálculo da pensão (leva em conta a expectativa de vida do aposentado) com o objetivo de reduzir a pensão padrão de $70 \%$ (dos rendimentos líquidos anteriores) para 64\% em 20,30.

A diminuição do tempo de concessão dos benefícios refere-se particularmente ao seguro desemprego. No Reino Unido, sua concessão foi reduzida de 12 para 6 meses e na Dinamarca, de 7 para 5 anos, em 1996\%. Ao mesmo tempo, na Bélgica, em 1996, foram abrandadas as condições de acesso: o desempregado pode requerer o seguro caso esteja sem emprego durante período correspondente a uma vez e meia à média da região (anteriormente a exigência era de duas vezes).

A redução do tempo de concessão do seguro desemprego só pode ser compreendida se associada a outras políticas atualmente desenvolvidas pelos países da União Européia. São os programas que visam "incentivar o trabalho" e "diminuir a dependência e a exclusão social". $O$ incentivo ao trabalho - dirigido a trabalhadores desempregados ocorre através da concessão de crédito familiar a partir do momento

${ }^{9}$ Um ano antes havia sido reduzida de 9 para 7 anos. 
que o trabalhador, com filhos, aceitar o emprego oferecido (Reino Unido) e da concessão de renda suplementar (Irlanda) ${ }^{10}$. Segundo a European Commission, o Reino Unido e diversos países também buscam incentivar os desempregados a aceitarem empregos a tempo parcial.

Ao mesmo tempo, diversos países têm buscado fomentar a criação de empregos de todos os tipos mediante redução de encargos e salários e concessão de incentivos diretos. Essas medidas visam, também, desenvolver oportunidades de empregos na chamada economia social. Na Bélgica, os empregadores que contratarem jovens e desempregados de longa duração recebem, durante três anos, redução substantiva de seus encargos sociais; já no Reino Unido, os empregadores que contratarem trabalhadores desempregados há dois anos têm reduçāo da carga durante 12 meses. Na França, o recrutamento de desempregado de longa duração há muito é subsidiado através da redução das contribuições.

\subsection{Restrição à aposentadoria e incentivo à aposentadoria parcial}

Diferentes países têm buscado atuar sobre a chamada aposentadoria precoce, isto é, aquela que envolve indivíduos com idade inferior a 65 anos. Para isso, dificultam o acesso ou promovem a redução do valor do benefício. Segundo a European Comission, essa foi a reação ao fato de, em 1996, quase a metade dos homens com idade entre 55 a 64 anos não serem economicamente ativos ${ }^{11}$.

Atualmente, na Suécia, a aposentadoria antes da idade oficial só é permitida para inválidos e mediante redução do valor da aposentadoria. Na Áustria, o tempo de contribuição para a aposentadoria plena foi aumentado de 35 para 37 anos e meio e, na Bélgica, o número de anos de contribuição aumentou de 20 para 35 anos. Tendo em vista que $o$ número de anos de contribuição é, assim como a idade, condição de acesso para a aposentadoria integral, o aumento do número de anos de contribuição visa reduzir a concessão de pensão para menores de 65 anos. Na Espanha e na Grécia, a aposentadoria voluntária antes dos 65 anos passou a ser penalizada. Ao mesmo tempo, alguns países estão

\footnotetext{
${ }^{10}$ A concessão de uma renda suplementar para familias de baixa renda, principalmente com filhos e monoparentais, foi também introduzida no Reino Unido e na Irlanda, em 1997.

${ }^{11}$ É curioso que essa instituição não se preocupou em dimensionar quantos desse contingente estavam inativos por terem permanecido por longo tempo desempregados.
} 
elevando a idade da aposentadoria plena, principalmente mediante a igualização das condições entre homem e mulher. Esse é o caso do Reino Unido, da Grécia e da Alemanha e mais recentemente, da Bélgica e da Áustria. A Tabela 3 apresenta a idade legal da aposentadoria integral para alguns países.

Tabela 3: Idade legal para a aposentadoria integral

\begin{tabular}{c|c|c|c}
\hline & 67 anos & 65 anos & 60 anos \\
\hline Dinamarca & $H / M$ & & \\
\hline Alemanha & & $H / M$ & \\
\hline Reino Unido & & $H / M$ & $H / M$ \\
\hline França & & & $H(62)-M(57)$ \\
\hline Itália & & & \\
\hline Espanha & & $H / M$ & \\
\hline Suécia & & $H / M$ & \\
\hline
\end{tabular}

Fontes: D'Intignano (1993), Anfip (1997) e European Commission (1998).

Ao lado do endurecimento das condições de acesso à aposentadoria antecipada, vários países estão incentivando a aposentadoria parcial junto àqueles com idade próxima à exigida para a aposentadoria integral. Nesse caso, o trabalhador continua trabalhando, mas em período parcial. Exemplos são encontrados na Alemanha (1993, para aqueles com 55 anos ou mais), na Áustria, em Luxemburgo, na Finlândia (desde 1980), no Reino Unido e na França (1993). Essa política deriva do fato de a contenção à aposentadoria antecipada não dar conta do conflito entre a presença de pessoas mais velhas no trabalho e o objetivo de reduzir o nivel do desemprego.

A aposentadoria parcial, contudo, encontra alguns obstáculos para sua plena utilização. Esse é o caso do Reino Unido, onde o trabalhador aposentado, mesmo que parcialmente, não pode continuar trabalhando para o mesmo empregador, necessitando buscar outra atividade. Como o emprego de pessoas de mais idade é difícil de ocorrer, pois um dos segmentos com maior participação no total dos desempregados é exatamente esse, a medida é pouco utilizada.

\section{Regime de repartição e regime de capitalização}

Nesses 25 anos de crise, apesar de todo o discurso liberal sobre a superioridade dos regimes privados de capitalização, não há nenhuma 
base para se afirmar que exista alguma tendência em substituir o payas-you-go por regimes de fundo, embora os fundos complementares (abertos e fechados) tenham apresentado grande expansão (European Commission, 1998). Mesmo assim, os únicos países em que os fundos de pensão ocupam um importante papel são a Holanda e o Reino Unido. No Reino Unido, em que o benefício básico concedido pelo Estado é muito baixo, $2 / 3$ dos pensionistas recebem pensão do sistema privado ou do fundo de sua categoria profissional.

\section{Políticas com relação à exclusão social}

Atualmente todos os países europeus contam com um beneficio do tipo renda mínima. Esse beneficio, que, na origem, se direcionava apenas aos não habilitados ao trabalho e às famílias de baixa renda, passou a contemplar situações de desemprego de longa duração. Nesse caso, contudo, sempre está associado a programas que visam reintegrar o trabalhador ao mercado de trabalho. O exemplo mais emblemático desse tipo de programa é encontrado na França, com a RMI (Renda Mínima de Inserção), implementado desde $1988^{12}$.

$\mathrm{Na}$ Itália, atualmente, a discussão ocorre em torno da possibilidade da substituição dos programas regionais por um nacional e do benefício ser relacionado ao tamanho da família. Já em Portugal, em que a renda mínima foi introduzida em 1997, há uma clara preocupação de, além da concessão da ajuda monetária, conceder treinamento e aconselhamento profissional com o objetivo de reintegrar o trabalhador na sociedade através do mercado de trabalho. Além disso, esse país considera importante garantir a assistência à criança e à saúde para o beneficiário da renda mínima. Preocupação semelhante à de Portugal está presente no programa dinamarquês iniciado em 1998. Nesse país, aqueles que recebem assistência social têm direito a retornarem ao ensino formal ou realizarem algum tipo de treinamento.

\section{A contenção do custo saúde e a nova agenda}

Pesquisadores de diferentes países, antes mesmo da crise econômica deteriorar as condições de financiamento da proteção social, chamavam atenção para o crescimento acentuado e contínuo do gasto com saúde e para a necessidade de serem implementados instrumentos que permitissem conter sua expansão. Entre os motivos apontados

\footnotetext{
${ }^{12}$ Para conhecer a abrangência e limitações do RMI, ver Marques (1997).
} 
para esse crescimento, destacavam: o envelhecimento da população; a ampliação da cobertura do risco saúde como decorrência da universalização; a crescente diversificação e complexidade da oferta de serviços médico-sanitários em função do franco desenvolvimento das técnicas de medicina e da incorporação do progresso técnico; o aumento da exigência do usuário e dos preços de seus bens e serviços, muitas vezes a taxas maiores que em outros setores; e os atuais currículos de medicina, que enfatizam a medicina curativa e o uso abusivo de exames.

A continuidade da expansão do gasto com saúde, em um ambiente de deterioração dos recursos públicos (provocada pelos juros altos praticados a partir do início da crise e pelas elevadas taxas de desemprego), levou vários países a adotarem controles mais rígidos sobre a execução do orçamento da área da saúde, a exigirem ou a aumentarem a participação do usuário no custeio dos medicamentos e da hospitalização e a implementarem mecanismos para restringir a despesa hospitalar. Na Inglaterra, isso chegou a conformar um novo arranjo entre o setor público e privado presente na assistência saúde.

Para melhor dimensionar o significado dessas medidas, recordemos como foi desenhada a organização e o financiamento da saúde pública no Welfare State. O sistema público, com exceção dos Estados Unidos e Japão, organizava-se através de um Serviço Nacional de Saú$\mathrm{de}^{13}$ ou de sistemas de seguro obrigatório. O primeiro constitui um sistema universal, em que o planejamento é definido centralmente e o financiamento é basicamente garantido por recursos de impostos, o que não impedia que fosse prevista a participação do usuário no custeio. Na Dinamarca, por exemplo, mesmo com hospitalização gratuita, era exigido que os $15 \%$ da população com renda mais elevada pagassem, no ato, a prestação de certos serviços. Esse pagamento era posteriormente reembolsado, mas nunca de forma integral. Em relação aos medicamentos, o Estado financiava apenas $25 \%$ de seu custo ${ }^{14}$. Já na Suécia, caso o usuário procurasse um serviço privado, o Estado reembolsava apenas $75 \%$ do valor pago a título de honorário médico e, para todas as situações, financiava apenas $50 \%$ do custo do medicamento ${ }^{15}$.

\footnotetext{
${ }^{13}$ Encontrado na Inglaterra (desde fins da Segunda Guerra), na Dinamarca (1955), na Suécia (1973) e na Itália (1978)

${ }^{14}$ A participaçāo do Estado aumentava para $75 \%$ para os 1000 medicamentos mais utilizados.

${ }^{15}$ Não era exigida nenhuma participação para os medicamentos relativos a 30 tipos de doenças crônicas.
} 
A participação do usuário no caso da Inglaterra, de valor fixo, era quase que simbólica. Por sua vez, o sistema de saúde do tipo seguro é encontrado na França, na Alemanha, na Bélgica e na Holanda. Como a organização tem por base as profissões, abrange vários regimes $\mathrm{e}$ apresenta cobertura diversificada. O traço comum é o direito à livre escolha de médico pelo usuário e o fato de os profissionais da saúde serem remunerados no ato ${ }^{16}$. Nesse sistema, as contribuições calculadas sobre a folha de salários constituem a principal fonte de recursos. Mesmo assim, a Alemanha sempre exigiu do usuário participação no custeio dos medicamentos através de um valor fixo ${ }^{17}$.

A primeira atitude realizada pelos governos para conter a elevação do gasto com saúde foi procurar atuar sobre o lado da demanda e da oferta de serviços. Do lado da demanda, houve generalização do uso do "tíquete moderador"18, agora aplicado não só ao custeio dos medicamentos, mas também às consultas médicas e às diárias hospitalares. Na Alemanha e na Suécia, houve redução da lista de medicamentos isentos de participação do usuário no custeio e adoção de um valor fixo para as diárias hospitalares. Em todos os casos, foi reduzido o percentual a ser reembolsado quando o paciente utiliza serviços privados. Também é importante mencionar que, em alguns países, foi exigida a participação no custeio da saúde de grupos até então isentos, tais como pensionistas e desempregados.

As açōes do lado da oferta, com exceção da política de contenção dos salários dos profissionais da área, foram praticamente dirigidas para reduzir o gasto hospitalar ${ }^{19}$. Os governos procuraram planificar a oferta hospitalar, conter as despesas, implantar sistemas de controle mais rigorosos sobre a execução dos orçamentos e desenvolver diferentes experiências de cálculo da diária. A contenção da despesa hospitalar foi buscada por intermédio da redução do tempo médio de permanência e do incentivo ao tratamento domiciliar (para isso destinaram um maior número de profissionais e, em vários países, passaram a remunerar as pessoas que se dispusessem a cuidar dos doentes em suas casas).

Já em relação ao controle do gasto hospitalar, destacam-se os chamados orçamentos globais, na Inglaterra, e os contratos de gestão ou

\footnotetext{
${ }^{16} \mathrm{Na}$ França, os segurados adiantam o pagamento, sendo reembolsados posteriormente.

${ }^{17} \mathrm{Na}$ França e na Bélgica não era prevista a participação do usuário no custeio dos medicamentos. ${ }^{18}$ Nome dado à exigência de participação do usuário no custeio de serviços e ações de saúde.

${ }^{19} \mathrm{Em} 1980$, na Suécia e na Inglaterra, a despesa hospitalar representou $73,3 \%$ e 70,2\% do total do gasto público com saúde, respectivamente
} 
serviços, na França. No primeiro, mediante uma programação orçamentária elaborada pela unidade hospitalar ou ambulatorial e negociada com a instância financiadora, foram realizadas transferências periódicas de recursos. De acordo com alguns pesquisadores, embora isso tenha permitido uma razoável previsibilidade do gasto, a ausência de parâmetros externos de eficiência e de um sistema permanente e eficaz de supervisão poderia levar à reprodução continuada da estrutura de custos (Medici, 1993 e Ugá, 1994). Contudo, de acordo com o Banco Mundial, a adoção do orçamento global permitiu, pelo menos, conter o aumento do gasto com saúde.

Podemos dizer que essas experiências, na medida em que são tomadas como estratégicas, integram uma nova agenda na área da saúde. De forma resumida, elas primam pela: a) adoção de mecanismos racionalizadores da assistência médica para reduzir o gasto hospitalar; b) ênfase nos serviços de atenção básica; c) separação entre quem financia e quem presta os serviços; d) introdução de mecanismos de mercado na assistência gerenciada (managed care) e/ou na competição administrada (managed competition); e) concessão de incentivos à oferta e à demanda com o objetivo de reestruturar a relação dos serviços públicos e privados, enfraquecendo o papel provedor do setor público (Almeida, 1999).

Nos últimos anos, diferentes governos europeus têm procurado tornar mais flexível a alocação dos recursos, separando as funções de financiamento das de provisão de serviços. Também vincularam o repasse de recursos à prestação de determinados serviços, impedindo que o agente executor tivesse "flexibilidade" de seu uso. Com essa medida, desconsiderou-se o repasse automático e global, que permitia o uso conforme as necessidades. O abandono do repasse automático significou a vinculação dos recursos a serviços previamente definidos, o quê, dependendo do gestor, pode levar à priorização somente daqueles considerados básicos, bem ao gosto das agências internacionais. Além disso, essa mudança foi acompanhada por um controle da execução que passava pelo cumprimento de indicadores de desempenho. Há quem defenda que essa nova sistemática pode facilmente levar a que o sistema preocupe-se somente com a assistência básica, deixando os procedimentos mais complexos para a iniciativa privada (Almeida, 1999). Esse é o caso dos sistemas do Reino Unido e da Suécia e das "Health Maintenance Organizations - HMOs, nos Estados Unidos (empregadores que compram planos de saúde para seus funcionários). Essas medidas têm fortalecido a intervenção reguladora do Estado; e, de 
maneira geral, ocasionaram maior controle sobre os custos. Podemos dizer que o resultado de sua aplicação foi estabilizar, nos últimos anos, o gasto com saúde em relação ao PIB (Tabela 4).

Tabela 4: Despesas com Saúde (\% do PIB)

\begin{tabular}{c|c|c|c|c|c|c|c}
\hline Paises & 1960 & 1970 & 1980 & 1990 & 1993 & 1995 & 1997 \\
\hline Canadá & 5,4 & 7,0 & 7,2 & 9,2 & 10,1 & 9,4 & 9,2 \\
\hline Dinamarca & 3,6 & 5,9 & 9,3 & 8,3 & 8,5 & 8,1 & 8,0 \\
\hline França & 4,2 & 5,8 & 7,6 & 8,9 & 9,8 & 9,8 & 9,6 \\
\hline Alemanha & 4,8 & 6,3 & 8,8 & 8,7 & 9,9 & 10,4 & 10,7 \\
\hline Holanda & 3,8 & 5,9 & 7,9 & 8,3 & 9,0 & 8,8 & 8,5 \\
\hline Noruega & 2,9 & 4,5 & 7,0 & 7,8 & 8,1 & 8,0 & 7,5 \\
\hline Suécia & 4,7 & 7,1 & 8,4 & 8,8 & 8,9 & 8,5 & 8,6 \\
\hline Biide & 3,9 & 4,5 & 5,6 & 6,0 & 6,9 & 6,9 & 6,8 \\
\hline EUA & 5,2 & 7,3 & 9,1 & 12,6 & 14,2 & 14,1 & 13,9 \\
\hline
\end{tabular}

Fonte: OCDE "Health Data 99".

\section{A Experiência dos Estados Unidos no campo da saúde}

No caso dos Estados Unidos, onde, na maior parte, o sistema é privado, tem crescido a regulação pública e privada através dos mecanismos de assistência gerenciada (managed care) nos seguros privados e da competição administrada (managed competition) nos sistemas da Califórnia e do Oregon (Almeida, 1999). Mesmo assim, o gasto com saúde vem crescendo ao longo das últimas décadas, ainda que nos últimos anos tenha se mantido estável. Sempre é bom relembrar que os EUA têm o sistema de saúde mais caro do mundo e, entre os países desenvolvidos, é aquele que apresenta a menor cobertura.

A reforma na área da saúde tem início na década de 80 . Nesse momento, o governo americano, com o apoio dos grupos empresariais e das grandes seguradoras, reorientou o sistema de saúde adotando a "competição administrada" (managed competition). O objetivo era conter os altos custos de cobertura dos seguros privados (principalmente aqueles pagos pelas empresas) e, ao mesmo tempo, garantir a liberdade de mercado no setor: Dessa forma, o modelo de "competição administrada" tinha o mesmo propósito que o modelo anterior - assistência à saúde gerenciada ${ }^{20}$

${ }^{20}$ A "atenção gerenciada" prevê a reatualizaçāo dos planos de saúde de pré-pagamento que fornecem assistência médica a grupos específicos através da negociação prévia de pagamentos e de pacotes assistenciais básicos. Privilegia o atendimento básico, definindo que a porta de entra- 
(managed care implantado nos anos 70): constituir uma alternativa que possibilitasse preservar a assistência médica empresarial, permitindo maior controle e contenção de custos, reduzindo a taxa de crescimento do gasto sanitário ${ }^{21}$.

O caráter inovador do modelo da "competição administrada" está na constituição de um mercado trilateral, formado por consumidores, planos de saúde e agentes coletivos responsáveis pela contratação de planos competitivos (tais como empregadores, organizações administrativas dos serviços de saúde ( HMOs) e agências governamentais). Segundo seus defensores, esse modelo permite criar um arranjo institucional que desenvolva a consciência de custos nos usuários e nos prestadores. Também pressupõe a participação dos "agentes coletivos responsáveis" para, através da competição, superar os problemas provocados pelas estratégias de lucro dos seguros privados.

Na prática, o modelo de "competição administrada" vem servindo para organizar as regras do jogo do mercado, e as organizações de "atenção gerenciada" seriam os atores desse "novo" mercado. Seus principais aspectos são: a) integração de seguradoras e prestadores de serviços em grandes operadoras para fortalecerem a venda de planos de saúde; b) surgimento de grandes organizações compradoras de seguros ("agentes responsáveis") com capacidade para definir o preço e a qualidade dos serviços; c) e diminuição das deduções no imposto de renda (pessoa jurídica e física) para os gastos que ultrapassem aqueles previstos no pacote negociado, induzindo a redução do consumo (Almeida, 1999). Embora esse modelo não tenha sido implantado no conjunto dos Estados Unidos, o que, para alguns analistas, é demonstrativo de seu fracasso, suas idéias de "competição administrada" recebem simpatias em países europeus, principalmente no Reino Unido.

A implantação da reforma inglesa ocorreu no início dos anos 90 , ainda que tenha sido gestada na década anterior, quando era clara a hegemonia das idéias neoliberais no governo Thatcher. Essa reforma priorizava o setor privado como executor das políticas, defendia a supremacia do econômico sobre o social, e do mercado sobre a "estrutu-

da do sistema seja via o médico generalista, reduzindo o acesso à atençāo especializada/hospitalar e controlando o desempenho desse profissional de acordo com critérios definidos que levam em conta os custos dos procedimentos da empresa.

${ }^{21} \mathrm{O}$ modelo de atenção gerenciada (managed care) foi institucionalizado em 1973 através do Health Maintenance Organizations Act, com a colaboração técnica e financeira das grandes fundações americanas - Kaiser Family Foudation, Robert Wood Johnson Foudation, etc. (Almeida, 1995). 
ra burocrática do Estado". A primeira medida realizada no corpo dessa reforma foi modificar os mecanismos de financiamento do Sistema Nacional de Saúde (National Health Service - NHS). O objetivo era aumentar a eficiência dos recursos. Para isso foram criados dois tipos de compradores (os "District Health Authorithies - DHAs e os General Practitioners - GPs) e dois tipos de prestadores (os "Hospital Trusts" hospitais transformados em "empresas" e os próprios "GPs - fundingholders", que passaram a gerenciar recursos financeiros para organizar a assistência aos clientes de suas listas). Além disso, foi adotada a terceirização dos serviços de hotelaria e do suporte hospitalar, e introduzidos esquemas de geração de renda adicional nos serviços, principalmente, através da cobrança de taxas específicas de utilização diretamente do paciente. A partir desse novo formato, a principal responsabilidade das autoridades públicas não é mais prover e gerenciar os serviços de saúde, mas garantir que esses estejam disponiveis quando necessários, ao menor preço. A reforma inglesa, portanto, enfatiza a separação entre provisão e financiamento, alterando a atribuição do Estado, que deixa de ser provedor, mas segue financiando, coordenando e regulando. Apesar da reforma, o gasto público com saúde não caiu em proporção do PIB. De fato, entre 1990 e 1993, apresentou um pequeno aumento da ordem de $0,9 \%$, mantendo-se constante a partir daí (Tabela 4).

\section{Cenário 1 - a continuidade da crise}

O cenário I funda-se em dois pressupostos básicos. O primeiro deles é que a crise instalada há 25 anos continue se arrastando, sem resolução ${ }^{22}$. O segundo é que os trabalhadores e demais interessados na manutenção dos sistemas de proteção social, construídos e desenvolvidos no pós-guerra, consigam manter o nivel de resistência atual, impedindo que os fundamentos dos sistemas sofram alteração substantiva. A caracterização dos últimos 25 anos como um período de crise considera: a) o acentuado descolamento dos ativos financeiros em relação ao

\footnotetext{
${ }^{22}$ A caracterização dos últimos 25 anos como um periodo de crise não recebe unanimidade na comunidade acadêmica. Gilberto Dupas, por exemplo, em seminário realizado em 24/02/2000 pela Associaçāo Nacional dos Fiscais Previdenciários (ANFIP), não considera relevante o fato de os lucros das empresas mundiais, dos últimos 10 anos, serem em parte compostos por ganhos obtidos junto ao mercado financeiro. O pensamento desse autor pode ser melhor apreendido em Dupas (1998)
} 
capital produtivo e às necessidades da economia (Plihon, 1995); b) o fato de os investimentos apresentarem média ou fraca dinâmica e serem altamente seletivos no plano espacial (Chesnais, 1994); c) os grandes grupos industriais dos Estados Unidos, Japão, Alemanha, França, Reino Unido e Itália terem conseguido recompor sua rentabilidade, a partir de 1981, somente graças ao aumento da taxa de exploração e à inclusão dos resultados obtidos junto ao mercado financeiro, muitas vezes de caráter especulativo (Husson,1996); d) o consumo mundial continuar retraído, refletindo o fraco crescimento da renda e o aumento da propensão marginal a poupar; e) a queda dos preços (apesar do aumento recente do petróleo) e f) a manutenção da garantida de expressivas taxas de juros ${ }^{23}$.

A forma prolongada da crise deve-se à permanência, apesar de todos os avanços do liberalismo, das estruturas e instituições criadas no auge do Welfare State. Entre elas, destacam-se a participação do gasto público em vários campos da atividade econômica e social e o papel de emprestador de última instância assumido pelo Estado (Chesnais, 1996a). Dessa forma, chamar o primeiro cenário de "Continuidade da Crise" deriva da hipótese de que a crise terá prosseguimento de forma "administrada", mesmo que, para isso, sejam utilizados instrumentos construídos durante o período de expansão da acumulação fordista. Como é sabido, os defensores mais radicais da supremacia do mercado defendem a extinção de todas as formas de intervenção do Estado que garantam pisos de renda e salários para os trabalhadores da ativa, aposentados e/ou desempregados.

\subsection{A proteção social nos países desenvolvidos}

Nesse cenário, a proteção social dos países desenvolvidos continuará a enfrentar dificuldades financeiras sérias, levando a que os governos intensifiquem as medidas até então tomadas. No campo previdenciário, o acesso à aposentadoria antecipada será cada vez mais restringido; o valor da pensão apresentará, cada vez mais, menor relação com o salário da ativa; e a idade de aposentadoria tenderá a aumentar. Apesar dessas restrições, não há qualquer possibilidade de a previdência pública voltar-se apenas para a concessão de um benefício mínimo ou para os segmentos mais carentes da população, o que im-

${ }^{23}$ Essa abordagem é desenvolvida em Marques (2000) 
plicaria sua substituição pelos fundos de pensão. Para que isso ocorresse, seria necessário que os trabalhadores e os setores interessados na manutenção dos sistemas atuais fossem absolutamente derrotados na luta de resistência que vêm realizando nesses últimos 25 anos. A rigor, essa derrota envolveria a quebra do estado de direito, o que não é possível no campo da democracia.

Mantida a democracia, não há Estado, por mais desenvolvido que seja o país, que possa substituir o sistema público pelo privado. Isso porque o custo da transição - tendo em vista o número de segurados em manutenção - seria extremamente elevado, e o aprofundamento do déficit público está fora da agenda dos países da União Européia. Seria impensável, por outro lado, que os fundos de pensão assumissem esse custo. Dessa forma, a única alternativa que restaria aos governos, mantida a crise, seria regular a idade de aposentadoria, o que não fere os fundamentos da proteção social. É perfeitamente justificável que o aumento da expectativa de vida seja acompanhado pela ampliação do tempo dedicado ao trabalho, posto que também se ampliou o número de anos que o trabalhador permanece apto para desenvolver sua ocupação.

A ampliação da idade, contudo, aprofundaria a problemática do desemprego, que exigiria exatamente a diminuição da oferta de força de trabalho. Devido a isso, é possível que assistamos, simultaneamente, ao aprofundamento do incentivo à aposentadoria parcial para aqueles próximos à idade de se aposentar e o crescimento do trabalho a tempo parcial para os demais trabalhadores. Contudo, os resultados observados da implementação dessas políticas, nos últimos anos, permite afirmarmos que seu impacto sobre as taxas de desemprego não é significativa. Esse fato define que os programas de garantia de renda ganharão cada vez mais importância no corpo dos sistemas de proteção social. Esses programas, associados ou não ao retreinamento da força de trabalho, serão o último degrau de sustentação de milhões de trabalhadores antes de entrarem na total indigência. Na hipótese da manutenção da democracia, as sociedades exigirão a garantia de renda mínima para aqueles expulsos do processo de produção da riqueza, não importando qual tenha sido o motivo.

Na saúde pública, também assistiremos à continuidade das medidas atuais, isto é, a exigência da participação do usuário no custeio; à busca de formas de assistência que não envolvam internação hospitalar; e a um controle cada vez maior em relação à oferta, visando diminuir seu poder de determinação dos procedimentos e dos medicamentos 
a serem adotados. Esta última possibilidade, envolveria desde alteração dos currículos de medicina - atualmente voltados à medicina curativa e ao uso abusivo de exames - até aumento da ingerência do Estado na política de medicamentos. Evidentemente que essa suposição, de continuidade das medidas atuais, descarta a possibilidade de a cobertura atual concedida pelo poder público ser reduzida a uma cesta básica, deixando para a iniciativa privada os demais serviços e ações. Tal como no campo previdenciário, a destruição do sistema atual exigiria tal mudança na relação de forças entre os diferentes atores, que seria impensável ocorrer no campo da democracia.

\subsection{A proteção social brasileira}

O cenário imaginado para os países desenvolvidos define, em grande medida, o que se pode esperar em termos de proteção social brasileira para os próximos anos. No tocante ao crescimento da economia, a previsão mais otimista não passaria de, para os melhores momentos, algo não muito diferente a uma situação stop and go. Essa previsão fundamenta-se na impossibilidade de o país engendrar um crescimento endógeno (tendo em vista os constrangimentos decorrentes da dívida externa e da política de juros), e de a alternativa, de o dinamismo ser puxado pelas exportações, ter pouca probabilidade de acontecer, pois é fundamentalmente dependente do crescimento do resto do mundo.

A presença esmagadora da dívida externa, carreando sistematicamente recursos para fora do país, impede que o país se volte para um crescimento mais voltado para o mercado interno e para o incentivo de atividades com baixo impacto na demanda de importados e intensivas em trabalho. Além disso, a necessidade de as taxas de juros manterem-se relativamente altas para garantir o afluxo de capital ao país, deprime o investimento, prejudica o crediário e aprofunda o déficit público, por maior que seja o superávit primário obtido mediante o corte de gastos muitas vezes fundamentais e o esforço de fiscalização. Nessa perspectiva, esperase que as taxas de desemprego mantenham-se altas e que o encolhimento do emprego formal - característica dos anos noventa após a entrada do Real - se aprofunde.

O impacto da deterioração do mercado de trabalho sobre as contas da Previdência já foi objeto de estudo anterior (Marques e Baticchi, 1999). O que talvez esteja ainda pouco explorado é o efeito do aumento da necessidade de financiamento da Previdência sobre os demais integrantes 
da Seguridade, principalmente da Saúde. A Tabela 5, que mostra a distribuição dos recursos da Cofins e da Contribuição sobre o Lucro Líquido (CSLL), é ilustrativa a esse respeito: entre 1996 e 1999, a Previdência Social brasileira aumentou sua participação no uso dos recursos da Cofins e da CSLL de $29,09 \%$ para $33,61 \%$.

Tabela 5: Distribuição da Cofins e da Contribuiçāo sobre o Lucro Líquido $-1996 / 97 / 99$ (\%)

\begin{tabular}{|c|c|c|c|c|c|c|}
\hline \multirow{3}{*}{ Cofins } & & Saúde & $\begin{array}{l}\text { Previdência } \\
\text { Social }\end{array}$ & Outras Áreas & $\begin{array}{c}\text { Retido Tes. } \\
\text { Nac. }\end{array}$ & Total \\
\hline & 1996 & 33,08 & 14,44 & 29,10 & 23,38 & 100,00 \\
\hline & 1997 & 27,56 & 44,40 & 18,72 & 9,32 & 100,00 \\
\hline \multirow{4}{*}{ CSIL } & 1999 & 15,37 & 17,08 & 42,22 & 25,33 & 100,00 \\
\hline & 1996 & 41,71 & 0,00 & 20,37 & 37,92 & 100,00 \\
\hline & 1997 & 48,90 & 6,76 & 1,03 & 43,31 & 100,00 \\
\hline & 1999 & 38,54 & 28,09 & 14,56 & 18,81 & 100,00 \\
\hline \multirow{3}{*}{$\begin{array}{l}\text { Total } \\
\text { Geral }\end{array}$} & 1996 & 38,54 & 28,09 & 14,56 & 18,81 & 100,00 \\
\hline & 1997 & 35,49 & 10,40 & 26,66 & 27,45 & 100,00 \\
\hline & 1999 & 33,68 & 33,61 & 13,65 & 19,06 & 100,00 \\
\hline
\end{tabular}

Fonte: SIAFI.

Desde maio de 1993, a Previdência Social deixou de partilhar com as demais áreas da Seguridade Social o produto da arrecadação das contribuições de empregados e empregadores. Naquele momento, essa medida afetou particularmente a Sistema Único de Saúde (SUS), que foi obrigado a decretar estado de calamidade pública para poder buscar junto ao Fundo de Amparo do Trabalhador (FAT) os recursos previstos no orçamento da União que não lhe foram transferidos. Nos anos que se seguiram a 1993, a situação financeira da Previdência Social somente piorou, embora o crescimento da despesa tenha voltado quase a seu ritmo normal, depois do impacto da entrada dos novos direitos garantidos pela Constituição de 1988, em 1993. O aumento da necessidade de financiamento deveu-se, basicamente, à deterioração do mer- 
cado de trabalho. Para se ter uma idéia, em 1999, a média mensal da arrecadação líquida foi praticamente igual à de 13 anos atrás (na verdade, foi $0,93 \%$ inferior a de 1986) e -7,87\% abaixo da realizada em 1996 .

O avanço da Previdência sobre os recursos da Seguridade aguçaram a disputa entre suas áreas e determinaram, enquanto argumento, a criação da Contribuição Provisória sobre a Movimentação Financeira (CPMF). Como é hoje largamente conhecido entre os pesquisadores da área tributária e/ou da Seguridade, o governo federal se valeu da arrecadação da CPMF para diminuir a participação da Cofins no financiamento da saúde. Isso foi possível porque, ao mesmo tempo, através do Fundo de Estabilização Fiscal (hoje Desvinculação dos Recursos da União - DRU, e antes ironicamente chamado de Fundo de Emergência Social), conseguiu ter poder de alocação de $20 \%$ da receita da Seguridade Social ${ }^{24}$.

É interessante destacar que, apesar da situação precária do mercado de trabalho brasileiro, o conjunto da Seguridade Social năo foi deficitário. Pelo contrário, em 1999, caso aplicássemos o conceito escrito na Constituição de $1988^{25}$ e desconsiderássemos o confisco dos $20 \%$ do FEF, teríamos um superávit de mais de $\mathrm{R} \$ 16$ bilhões, o que permitiria que a Previdência respondesse mais tranqüilamente a seus compromissos. A Tabela 6 apresenta a composição da receita e da despesa da Seguridade Social, demonstrando quão significativo foi seu superávit.

É claro que em parte esse superávit é definido pelo nível de gasto acordado na Lei Orçamentária. Principalmente na área da saúde, é sabido que a carência de recursos impede, de maneira geral, a concessão de níveis adequados de atendimento para os demandantes do SUS. A falta de medicamentos, de equipamentos e de pessoal muitas vezes compromete até mesmo a continuidade de programas como o de assistência aos portadores do HIV o de combate à dengue.

\footnotetext{
${ }^{24}$ A situação financeira da Previdência Social determinou que o percentual de $20 \%$ nunca fosse aplicado sobre as contribuições de empregadores e empregados.

${ }^{25}$ Segundo o Artigo 194 da Constituiçāo de 1988, a Seguridade Social é composta pela Previdên cia, pela Saude, pela Assistência e pelo programa de seguro desemprego. Ainda segundo ela, todas as suas ações e benefícios são financiados através das contribuiçōes calculadas sobre os salários, faturamento (Cofins e Pis/Pasep) e lucro, bem como do resultado de concursos e prognósticos e do aporte das três esferas do governo. Apenas o Pis/Pasep seria reservado exclusivamente para o financiamento do abono e para o programa seguro desemprego. Os demais comporiam a cesta de recursos da Seguridade Social e, a cada ano, sua partilha seria definida na Lei Orçamentária.
} 
Tabela 6: Receitas e Despesas da Seguridade Social - 1999 (Em R\$ bilhões)

\begin{tabular}{l|c}
\hline Receitas & 1999 \\
\hline Arrecadação líquida de contribuiçôes & 49,128 \\
\hline Outras Receitas do INSS & 0,368 \\
\hline Cofins & 30,797 \\
\hline Contr. Sobre o Lucro Líquido & 6,736 \\
\hline Concurso de Prognósticos & 0,991 \\
\hline CPMF & 7,949 \\
\hline Fundo Nac. de Assistência Social & 0,589 \\
\hline Fundo Nac. de Saúde & 0,578 \\
\hline Total das Receitas & 97,136 \\
\hline Despesas & 1999 \\
\hline Benefícios Previdenciários & 58,540 \\
\hline \multicolumn{1}{c|}{ Urbanos } & 47,726 \\
\hline Rurais & 10,814 \\
\hline Benefícios Assistenciais (Loas e RMV) & 1,546 \\
\hline Assistência Social Geral & 0,984 \\
\hline Saúde & 18,047 \\
\hline Outras Despesas de Custeio do MPAS & 1,758 \\
\hline Total das Despesas & 80,875 \\
\hline Saldo & 16,261 \\
\hline
\end{tabular}

Fonte: SIAF/99 e COGEFIN/INSS. Elaboração: ANFIP.

Apesar do resultado expressivo da Seguridade Social, o governo, durante todo o ano de 1999, continuou a confundir a opinião pública. Suas diversas declarações a respeito do déficit da Previdência acabaram por facilitar a aprovação no Congresso da Lei $n^{\circ} 9.876$, que institui o "fator previdenciário". Esse tem por objetivo definir o valor do benefício em função do tempo de contribuição e da expectativa de sobrevida do segurado no momento do requerimento da aposentadoria. Além disso, a base de cálculo passou a contemplar todo o período de contribuição, o que, por si só, reduz o valor a ser pago.

De maneira geral, portanto, a falta de perspectiva de crescimento da economia brasileira e o aprofundamento do desemprego e da precarização do mercado de trabalho tenderão a dificultar o financiamento da Previdência Social e a tornar cada vez mais tensa a relação dessa área com as demais da Seguridade Social. 


\section{Cenário 2 - O retorno do círculo virtuoso}

Esse cenário considera o retorno sustentado da economia mundial. Como pressuposto, considera a recuperação da rentabilidade do setor produtivo, comparável à existente no período de auge do fordismo, e a diminuição da atual autonomia relativa do capital financeiro. Junto ao mercado de trabalho, o novo ciclo de expansão provocaria uma situação de quase pleno emprego, sem, contudo, restabelecer as relações empregatícias do período anterior.

\subsection{A situação nos países desenvolvidos}

Na hipótese de a economia mundial voltar a crescer de forma sustentada, permitindo a incorporação dos novos integrantes do mercado de trabalho e a diminuição sucessiva do estoque de desempregados de longa duração, certamente veremos diminuir a importância financeira e social dos programas de seguro-desemprego e mesmo daqueles de tipo renda mínima nos países desenvolvidos. Ao mesmo tempo, assistiremos à recuperação da capacidade arrecadatória do Estado, facilitando a manutenção daqueles programas cujo financiamento fundamenta-se em grande parte nos recursos fiscais.

Contudo, se alguns dos traços atuais do mercado de trabalho persistirem, tais como a importância crescente da ocupação dos não assalariados, dificilmente poderemos dizer que os sistemas organizados a partir das contribuições sociais não continuarão a apresentar problemas financeiros. A hipótese de aumento da importância do trabalho não assalariado, muitas vezes chamado de autônomo ou terceirizado, deriva da possibilidade de as empresas preferirem manter estratégias de contratação de empreitada no lugar da permanência de determinados tipos de trabalhador e do fato de essas atividades poderem ser desenvolvidas fora da empresa. Essa preferência, por sua vez, seria resultado, não de uma demanda incerta tal como atualmente, mas de sua constante mudança quanto ao gosto e qualidade ${ }^{26}$.

O crescimento relativo do trabalhador não assalariado, diminuindo a base de sustentação dos sistemas de proteção social financiados fundamentalmente através das coṇtribuições calculadas sobre o salá-

${ }^{26}$ Vários autores, entre eles Coriat, estabelecem uma clara relação entre novas tecnologias e demanda retraída. As novas tecnologias, por serem flexiveis, permitem que a empresa rapidamente se adapte às variaçōes da demanda (Coriat, 1985). 
rio, exigiria a construção de um novo arranjo social. Um dos arranjos possiveis seria supor que, pouco a pouco, a base de cálculo deixasse de ser o salário e fosse adotada outra, mais ampla, como a renda. Essa alternativa já é adotada nos países onde o sistema de proteção social é financiado mediante os recursos do Estado e o instrumento utilizado é o imposto de renda. Outra alternativa seria fundar a contribuição dos não assalariados sobre a renda corrente, organizando-os em regime à parte ou integrando-os ao mesmo regime geral, já existente.

Qualquer dessas duas alternativas não é isenta de problemas. Na primeira, embora a contribuição fosse facilmente aplicada, posto que integraria o imposto de renda, os problemas da partilha dos recursos entre a esfera social e fiscal poderiam se agudizar. A solução seria, nesse caso, definir quantos pontos percentuais do imposto seria vinculado ao Fundo da proteção social. Na segunda alternativa, todo o problema deriva do fato de a contribuição não ser compulsória. Dada a característica humana que privilegia o momento atual e descuida-se do futuro, é possivel que, tal como acontece no Brasil, a contribuição efetuada pelos não assalariados seja a mais baixa possível, isto é, calculada sobre renda declarada muito inferior à real. Essa situação não só dificultaria o financiamento dos benefícios atualmente pagos (dado que os regimes são de repartição simples), como provocaria problemas sociais futuros, pois a aposentadoria a que teriam direito esses contribuintes seria a mínima, rebaixando sobremaneira seu nivel e qualidade de vida. Dificuldades semelhantes estariam postas para o financiamento da área da saúde, exigindo que o Estado aumentasse sua participação no financiamento, para complementar a arrecadação das contribuições calculadas sobre os salários e as rendas (dos não assalariados).

Ao mesmo tempo, para todos os países, continuariam os problemas na área da saúde decorrentes do envelhecimento da população, do aumento da expectativa de vida, da constante incorporação de novas tecnologias na medicina, entre outros. Esses problemas, tais como hoje, envolveriam situações éticas e morais de dificil solução, em que os princípios racionais do custo/benefício da microeconomia, por mais que os gestores tentem, são de difícil aplicação.

\subsection{A proteção social brasileira}

O Brasil estaria vivendo também um período de crescimento, em parte em função do crescimento do resto do mundo e da redução das 
taxas de juros mundiais. Isso melhoraria a capacidade de financiamento do Estado, muito embora os problemas derivados da dívida externa continuariam presentes, exigindo soluções negociadas mais de longo prazo.

No tocante ao mercado de trabalho, haveria queda do desemprego, tanto através do aumento do emprego formal como da ocupação dos chamados autônomos. Essa melhora do mercado de trabalho provocaria aumento da arrecadação da Previdência Social, diminuindo ou eliminando sua necessidade de se apoiar sobre recursos da Cofins e da Contribuição sobre o Lucro Líquido ${ }^{27}$. Dessa forma, as tensões entre as diferentes áreas da Seguridade Social tenderiam a diminuir, o mesmo ocorrendo na relação Seguridade e Tesouro Nacional. Isso não eximiria, entretanto, da realização de reformas no corpo da Seguridade, principalmente aquelas que redesenhassem a relação público e privado e contemplassem a participação efetiva dos interessados.

Contudo, tais como nos países desenvolvidos, a presença crescente de trabalhadores não assalariados exigiria um esforço significativo do atual sistema de proteção. Mais do que hoje, se faria necessário integrar esses trabalhadores ao regime geral, o que teria como pressuposto não só a existência de uma fiscalização mais rigorosa, mas, principalmente, a cooptação voluntária desses trabalhadores. Para isso, entretanto, a imagem da Previdência Social precisaria ser radicalmente alterada, de forma que o trabalhador de todos os tipos nela reconhecesse a provedora de sua aposentadoria futura.

\section{Considerações finais}

Na parte introdutória desse artigo, perguntávamos se os constrangimentos que atuam negativamente sobre a proteção social poderiam exigir a construção de um novo modelo ou se, até mesmo, colocariam em questão qualquer tipo de proteção que tivesse como pressuposto o coletivo. Analisadas as mudanças que ocorreram nesses 25 anos de crise, verificamos que, apesar das medidas restritivas implementadas pelos diversos governos, não se pode afirmar que houve um retrocesso em matéria de proteção social. Pelo contrário, as medidas adotadas tentam preservar a proteção universal em uma situação de deterioração financeira e de en-

\footnotetext{
${ }^{27}$ Este artigo está desconsiderando a proposta de reforma tributária atualmente em discussão no Congresso Nacional. Como é sabido, ela prevê a extinção da Cofins e da Contribuição sobre o Lucro Líquido e a criação de uma Contribuição Social Geral, o que, de acordo com vários pesquisadores, poderá aumentar o conflito no interior da Seguridade Social
} 
velhecimento significativo da população. Para isso, aumentam a idade da aposentadoria, exigem maior contribuição do segurado e do usuário. Mas ainda os sistemas são fundados na solidariedade entre gerações, na repartição simples e no véu da ignorância ${ }^{28}$.

A desproteção, que é claramente evidente, não decorre das mudanças realizadas nos diferentes sistemas. Deriva, sim, é da ausência de empregos para todos. Como bem explorou Castel (1996), em nossas sociedades, a proteção e a integração social dos indivíduos realizam-se via o trabalho: é através dele que é garantida nossa participação na produção da riqueza de hoje e os meios (a pensão por aposentadoria) de acesso à nossa participação no amanhã.

É nossa conclusão que, mantida a crise em um ambiente democrático, assistiremos ao reforço das medidas já encaminhadas, mas não à substituição dos sistemas atuais por outros baseados nos princípios do individualismo e do mercado. Contudo, caso as economias voltassem a crescer de forma sustentada e a ocupação sem vínculo empregatício demonstrasse ser permanente, aí sim estaria sendo colocada em questão a engenharia social construída no pós-guerra. Certamente a substituição (ou seu mix) do trabalho pela renda, como base do financiamento exigiria o repensar dos atuais sistemas.

No caso brasileiro, nenhum dos dois cenários seria muito animador. Embora o crescimento da economia mundial favoreça o desempenho interno, melhorando a situação financeira da Previdência Social e sua relação com as demais áreas da Seguridade, o aumento do já amplo setor informal seria perturbador. Isso porque a adesão ao regime geral dos trabalhadores de novo tipo (não assalariados) exigiria a mudança da atual imagem da Previdência Social, o que levaria algum tempo.

\section{Referências bibliográficas}

ALMEIDA, C. M. As reformas sanitárias nos anos 80: crise ou transição? Rio de Janeiro, tese de doutorado, Escola Nacional de Saúde Pública, Fundação Oswaldo Cruz, 1995.

. "Reforma do Estado e reforma de sistemas de saúde: experiências internacionais e tendências de mudança”. Ciência $\mathcal{E}$ Saúde Coletiva. Rio de Janeiro, Abrasco, v. 4, n 2, 1999.

${ }^{28} \mathrm{~A}$ expressāo véu da ignorância refere-se ao fato de, no regime de repartição simples, nenhum segurado saber, ex-ante, se terá vantagens ou desvantagens (Van Parijs, 1994). 
CASTEL, R. Les metamorphoses de la question sociale - Une chronique du salariat. Paris, Fayard, 1995.

CHESNAIS, F. La mondialisation du capital. Paris, Syros, 1994.

.Quelques éléments de réponse aux remarques de Claude Serfati". Carré Rouge, Paris. Carré Rouge, n 3, p. 17-34, outubro de 1996 (a).

CORIAT, B. "Crise e automação eletrônica da produção - robotização da fábrica e modelo fordiano da acumulação de capital”. Pesquisa e Debate. São Paulo, Programa de Estudos Pós-graduados em Economia, PUC-SP, $\mathrm{n}^{\circ} 1,1985$.

DUPAS, G. "O novo paradigma do emprego". São Paulo em Perspectiva. São Paulo, Fundação Seade, v. 12, n 3, 1998.

EUROPEAN COMMISSION. "Social Protection in Europe - 1997". França, Eurostat - ESSPROS, 1998.

GORZ, A . Adeus ao Proletariado: para além do socialismo. RJ, Forense Universitária, 1982.

HUSSON, M. Misère du capital: critique du néolibéralisme. Paris, Syros, 1996.

KEYNES, J. M. A teoria geral do emprego, do juro e da moeda. São Paulo, Abril Cultural, 1983.

MEDICI, A. C. Aspectos teóricos e conceituais do financiamento das políticas de saúde. São Paulo, 1993, mimeo. Texto elaborado para publicação da ABRES.

MARQUES, R. M. A proteção social e o mundo do trabalho. São Paulo, Bienal, 1997.

. "Notas sobre a reforma previdenciária brasileira no contexto do neoliberalismo e da América Latina". Revista de Economia Política. São Paulo, Editora 24, v. 20, no 1 (77), janerio-março/2000, p. 138-148.

"Será a presente crise 'o crepúsculo de um ciclo unificado de valorização assentado na dominação do capital industrial'?" Porto Alegre, Revista Ensaios FEE, n 21 , no prelo.

MARX, K. O capital, Livro III, vol. V. São Paulo, Civilização Brasileira, $3^{a}$ edição, 1981.

MATTOSO, J. "O novo e inseguro mundo do trabalho nos países avançados". In Oliveira, C. A . B. (org). O mundo do trabalho - crise e mudança no final do século. São Paulo, Editora Página Aberta, 1994. 
. O Brasil desempregado: como foram destruídos mais de 3 milhões de empregos nos anos 90. São Paulo, Fundação Perseu Abramo, 1999. PLIHON, D. "A ascensão das finanças especulativas". Economia e Sociedade. Campinas, Instituto de Economia da Unicamp, (5), p. 61-78, dezembro de 1995.

RIFKIN, J. O fim dos empregos: o declínio inevitáuel dos níveis de empregos e a redução da força global de trabalho. São Paulo, Makron Books do Brasil Editora Ltda, 1995.

UGÁ, M. A. D. "Sistemas de repasses financeiros a unidades de assistência à saúde: uma proposta preliminar para a rede pública brasileira". In Vianna, S. M. et al. Financiamento da saúde no Brasil. Brasília, OPAS, 1994.

VAN PARIJS, PH. "AU delà de la solidarité. Les fondementes éthiques de l'Etat-providence et de son dépassement". Futuribles. Paris, Futuribles Sarl, n 184, p. 05-29, fevereiro, 1994. 